This item was submitted to Loughborough's Research Repository by the author.

Items in Figshare are protected by copyright, with all rights reserved, unless otherwise indicated.

\title{
Multidisciplinary research: should effort be the measure of success?
}

PLEASE CITE THE PUBLISHED VERSION

http://dx.doi.org/10.1080/09613218.2016.1194601

\section{PUBLISHER}

(C) Taylor \& Francis

\section{VERSION}

AM (Accepted Manuscript)

\section{PUBLISHER STATEMENT}

This work is made available according to the conditions of the Creative Commons Attribution-NonCommercialNoDerivatives 4.0 International (CC BY-NC-ND 4.0) licence. Full details of this licence are available at: https://creativecommons.org/licenses/by-nc-nd/4.0/

\section{LICENCE}

CC BY-NC-ND 4.0

\section{REPOSITORY RECORD}

Buswell, Richard A., Lynda H. Webb, Val Mitchell, and Kerstin Leder Mackley. 2019. "Multidisciplinary Research: Should Effort Be the Measure of Success?". figshare. https://hdl.handle.net/2134/21632. 


\title{
Multidisciplinary research: should effort be the measure of success?
}

\author{
Richard Buswell ${ }^{*}$, Lynda Webb ${ }^{1}$, Val Mitchell ${ }^{2}$ \\ and Kerstin Leder Mackley ${ }^{2}$ \\ ${ }^{1}$ Building Energy Research Group, Loughborough University, UK \\ ${ }^{2}$ Loughborough Design School, Loughborough University, UK \\ * Corresponding Author: r.a.buswell@lboro.ac.uk
}

\begin{abstract}
Energy demand reduction and flexible demand from dwellings will play a critical role in achieving a low carbon future. There remain many unanswered questions around the interaction of people with their environment and the technical systems that service them and as a result, multidisciplinary research is a principle component of research funding internationally. There is, however, relatively little published work that considers the operational issues in undertaking epistemologically diverse, academic research projects. This paper makes a contribution by quantifying the operational effort involved in data collection on a large multidisciplinary project and connecting the operational issues encountered to knowledge production. The paper finds that cost of the data gathering to be $£ 46,000 /$ home and participants can give upwards of 217 hours of their time per house, engaging with data gathering activities. The rate of knowledge production is found to be approximately 3 publication/FTE over the lifetime of the project and the risk to generating interdisciplinary insights is shown to be dependent on largely unforeseeable operational issues that compound the characteristic differences in the collection of the data utilised by social and technical research communities.
\end{abstract}

\section{Keywords}

Energy; project management; multi-disciplinary research; project planning 


\section{Introduction}

Energy demand reduction and flexible demand from dwellings will play a critical role in achieving a low carbon future reflected in EU policy (EPBD, 2010; Energy Efficiency Plan, 2011), many if not all future energy system scenarios, pathways and carbon budgets in the UK (Quiggin and Buswell, 2016; Energy Technologies Institute (ETI, 2015); CCC, 2015) and in North American energy strategies, (Brook et al., 2012; California Energy Commission, 2015). Energy efficiency is considered to be a low carbon technology by the Low Carbon Innovation Coordination Group (LCICG, 2014), who highlights the importance of energy efficiency and the complexity and interconnected nature of technologies and users. Indeed, it is widely accepted that energy demand reduction is not just a technological problem, but includes occupants and their interrelations with the building, its systems and controls (Department of Energy and Climate Change, DECC, 2014).

Understanding people, their interactions with buildings and the systems that service them requires new knowledge and the answer to many of the important questions lie on the boundaries of traditional research disciplines (European Commission, 2015; Research Council's UK, 2015). Many contemporary research projects in the field of energy and the built environment have an aspiration to deliver interdisciplinary insights (Lomas, 2010; Hazas et al., 2011; Sovacool, 2014; Sovacool et al., 2015), but is this realistic? Can we expect projects to deliver interdisciplinary knowledge? Or should we accept, as Atkinson (1999) suggests, that the quality of the research a project generates is an 'emergent property of peoples different attitudes and beliefs' (p337) and hence many projects will only deliver mono and/or multidisciplinary work, where insights appear more like a jigsaw, rather than a Kaleidoscope (Newell and Swan, 2000; Winskel et al., 2015). If interdisciplinary insights cannot be guaranteed, should the effort in delivering such projects be the measure of their success, rather than the prestige of the journal in which results are published, which are biased towards mono-disciplinary work (Rafols et al.)?

This paper first takes a cross-field view of the work that relates to multidisciplinary project working and knowledge generation in an attempt to bring together the research themes around multidisciplinary research in energy and the built environment. These themes are:

1. organisational frameworks;

2. knowledge generation;

3. project success and the barriers to this;

4. the effect of temporary project teams;

5. the relationships between team members; and,

6. the integration of social science within projects.

What becomes apparent is that 'effort' has two attributes: one defined by the personal and emotional investment by researchers; and the other the time and cost involved in enabling such research. Much of the literature addresses the former issue, but there is very little, if any work focusing on the latter. 
To help bridge this gap, the work presented here takes a different approach to other studies by examining the project's operational activities that lie behind multidisciplinary data collection. By doing so it takes a bottom up approach to quantify the effort (time and cost) involved in implementing a project, building on this to understand the factors that influence the synchronicity of disciplinary knowledge generation. The work is based on a case study: a large single institution academic research project undertaken in the UK between 2010 and 2014. When thinking of 'multi-disciplinarity', this paper talks more to the epistemological and ontological distance between human oriented disciplines related to the Social Sciences, User Centred Design and Psychology and the technical disciplines of Engineering, Building Physics and Computer Science. In this work, these disciplines are placed into two broader groups, reflecting Love and Cooper's (2015) classifications of 'social' and 'technical' research.

\section{Literature Review}

Multidisciplinary project literature spans the social sciences, medicine, education, project planning and management, innovation studies, psychology, knowledge management, research policy as well as energy and the built environment. Across these disciplines the literature speaks to the 6 topic areas listed above and 5 core issues emerge.

\section{The creation of knowledge and how it is shared between individuals}

The interest in knowledge management is growing due to the recognition of the increasing value of knowledge in advancing economies and is influencing the focus of studies across academia and industry. Studies have focused on frameworks and models to describe this process as well as evaluating the effectiveness of organisational frameworks at shaping project outcomes (Huang and Newell, 2003; Lander, 2016; Hunter et al., 2011; Wang, 2016; Martin-deCastro et al., 2008). A number of models of knowledge creation have been developed (Hessels and Lente, 2008; Berker and Bharathi, 2012). Knowledge generation in temporary projects has emerged as a sub-theme with new models offered to describe knowledge transfer within organisations, (Lindner and Wald, 2011) and identifying discipline boundaries (Fong, 2003) but none describe the generation of knowledge as it relates to the operational issues on projects.

\section{The organisational framework within which research takes place}

Most contemporary academic research projects are temporary groupings of academics and researchers. In the UK there are examples of longer running initiatives (UK Energy Research Centre, the Innovative Manufacturing Research Centres, and the SuperGen Hubs are examples). These offer a more stable platform, yet are still populated with individuals who may be transitory and 
usually not dedicated to the research task in the same sense as members of an industrial research and development centre might be. The European research institutions (for example, CSTB in France, ENEA in Italy and AIT in Austria) offer dedicated research facilities, but funding through the European framework programs will tend to drive the formation of temporary project groupings between institutions and industrial partners. Such methods of working tend to lend themselves to the lingering of specific knowledge within an organisation, or one part of the same organisation, but the collective knowledge at the end of the project is likely to fragment and become lost as the team dissolves (Lindner and Wald, 2011; Fong, 2003); a problem exacerbated in the UK through the short fixed term contract approach to staffing research projects in academic institutions.

\section{The spatial location of team members and their relationships}

The influence of the spatial location of team members on the effectiveness of multidisciplinary projects has been investigated by Cummings and Kiesler (2007), who examined the cost effectiveness of the additional overhead involved in enabling multi-institution collaborations to meet and share knowledge. They found that greater numbers of institutions complicates coordination and reduces outcomes (new knowledge creation, new tools, training students, etc.), although the evidence was not sufficient to generalise beyond their study. In fact a rule of thumb suggested by Allen (1977) and Kraut et a. (1990), (cited by Cummings and Kiesler, 2007) was that co-workers should be no more than 30 metres apart, which can in practice be difficult to achieve with researchers within the same institution and all but impossible across different institutions. This closeness of team members was echoed by Hautala and Jauhiainen (2014) who recognised the value of team members 'being there' for face-to-face communication.

Newell and Swan (2000), focused on the trust between team members of an inter-university, multidisciplinary project based in the UK. A key acknowledgement was the time taken to develop trusting relationships, particularly on a complicated project that has a team with very different epistemological stances, which challenges the time pressures highlighted by Winskel et al. (2015). Their findings also suggest that more time is required for such projects if team knowledge is not to become fragmented and lost, reinforcing the findings of Lindner and Wald (2011).

\section{Working across research discipline boundaries}

Research into project based multi or interdisciplinary working is often carried out from the perspective of the integration of social science with other disciplines, for example: Campbell (2005), Jacobs and Frickel (2009) and Younglove-Webb et al. (1999). Much of the literature reviewing the obstacles, trials and tribulations of implementing multidisciplinary teams comes out of the US (Jacobs and Frickel, 2009; Golde and Gallagher, 1999; Metzger and Zare, 1999) however there are examples from the UK and Europe (Lowe and 
Phillipson, 2009; Mallaband and Haines, 2014; Waterton et al., 2006; Bracken and Oughton, 2006; Saddon, 2015). Emerging themes from these studies are around issues of language and communication, respect for other disciplines, the need for regular contact with team members and taking time to build relationships.

\section{The identification of barriers to and the measurement of success}

How successful multidisciplinary projects are remains an open debate (Rhoten, 2004). What constitutes a valid measure of success has in itself generated considerable attention in the literature (Ika, 2009). Within studies focused on academic projects, taxonomies of success indicators have been discussed (Dvir et al, 2003) within which publications feature as an important measure of knowledge generation (Porac, et al, 2004). This is tempered, however by the difficulty in gaining recognition for multidisciplinary publications in prestigious journals with high impact factors (Togia and Tsigilis, 2006; Rafols et al, 2012).

\section{Summary}

The literature identifies several reoccurring issues that are of importance in successful multidisciplinary collaborations:

- inter-personal relationships;

- respect for other disciplines;

- trust between team members;

- location of the team;

- time and space given to multidisciplinary endeavour; and,

- the active promotion of its value within the team.

The first 3 of these represent the inter-personal effort expended by the individuals that are members of a team. The last 3 issues represent effort expended in the project management and there is little if any work that quantifies the time and cost associated with multi-disciplinary project operations, principally the data collection process that underpins research. This shortcoming is addressed in this paper.

\section{Methodology}

A bottom up approach has been taken using detailed project records combined with informal interviews and discussions with project staff to generate a map of the project timeline onto which research effort and knowledge production can be plotted. Overlaid onto this are the rates of data production and a discussion of the operational issues that hamper this process. The project timeline is characterised here using four phases: planning; [household] recruitment; data 
Table 1 The TEDDI projects principally involved in understanding domestic energy demand reduction and how it relates to ICT

\begin{tabular}{|c|c|c|c|c|}
\hline Project & Theme & $\begin{array}{c}\text { Duration } \\
\text { (years) }\end{array}$ & Institutions & $\begin{array}{r}\text { Award } \\
(£ k)\end{array}$ \\
\hline APAtSCHE & Automation controls in social housing & 2 & $\mathrm{~m}$ & 754 \\
\hline IAHM & Agent based visualisation & 4 & $\mathrm{~m}$ & 813 \\
\hline REFIT & Smart controls and demand reduction & 3 & $\mathrm{~m}$ & 1,500 \\
\hline LEEDR & Behaviour and demand reduction & 4 & s & 1,400 \\
\hline DEFACTO* & Effect of smart controls on demand & 5 & S & 1,500 \\
\hline ENLITEN $^{*}$ & Modelling demand reduction & 4 & s & 1,500 \\
\hline IDEAL $^{*}$ & Reduction through feedback & 4 & s & 1,700 \\
\hline Smart' h'holds* & Energy reduction, feedback, gaming & 5 & $\mathrm{~m}$ & 1,100 \\
\hline
\end{tabular}

* Indicates that the project has not been completed at the time of publication.

gathering; and, analysis and publication. Project events and operational issues reported by the project team are unpacked and the impact on effort and knowledge production is examined.

\section{Case study description}

The UK government research budget for $2015 / 2016$ is $\sim £ 4.7 \mathrm{bn}$, of which $£ 2.7 \mathrm{bn}$ is allocated to the research councils (BIS, 2014). The TEDDI (Transforming Energy Demand through Digital Innovation) projects were funded through the Energy and Digital Economy programs, where the total award was $£ 23 \mathrm{~m}$ for the 22 projects that constitute the TEDDI/buildTEDDI group in the period 2010 to 2018. Table 1 lists the projects that are more closely focused on understanding energy demand in the home. Other projects focused on commercial spaces, individual consumption and on technology (mainly sensing, wireless networks and communications). Of those researching energy demand in the home, there are four that are longer studies that involve owner-occupied family homes, two of which have been completed: LEEDR and REFIT. These both have user centred design, social science and engineering expertise in the teams. Both have samples of 20 households. LEEDR is a single institution project, while REFIT involved several institutions. LEEDR is the project upon which this case study is based and metrics established from the REFIT are used as comparators in the discussion.

The LEEDR project was a four-year study that explored energy consumption in family homes. 20 households took part over the course of 3 to 4 years with the aim of understanding how to design and develop energy reduction interventions that would fit with the grain of everyday family life. The research disciplines and their interaction envisioned at inception are illustrated Figure 1. The 'social' research team comprised of two disciplines, user-centered design and an anthropologically informed approach to sensory ethnography. The 'technical' disciplines are represented by the 'engineering' label, but actually comprise of people with specialisms in electrical, mechanical and systems engineering as well as computer science. To coordinate the project and to encourage mixing between the disciplines the single institution nature of the project meant that the project team were able to meet regularly with a large subset of the 14-15 


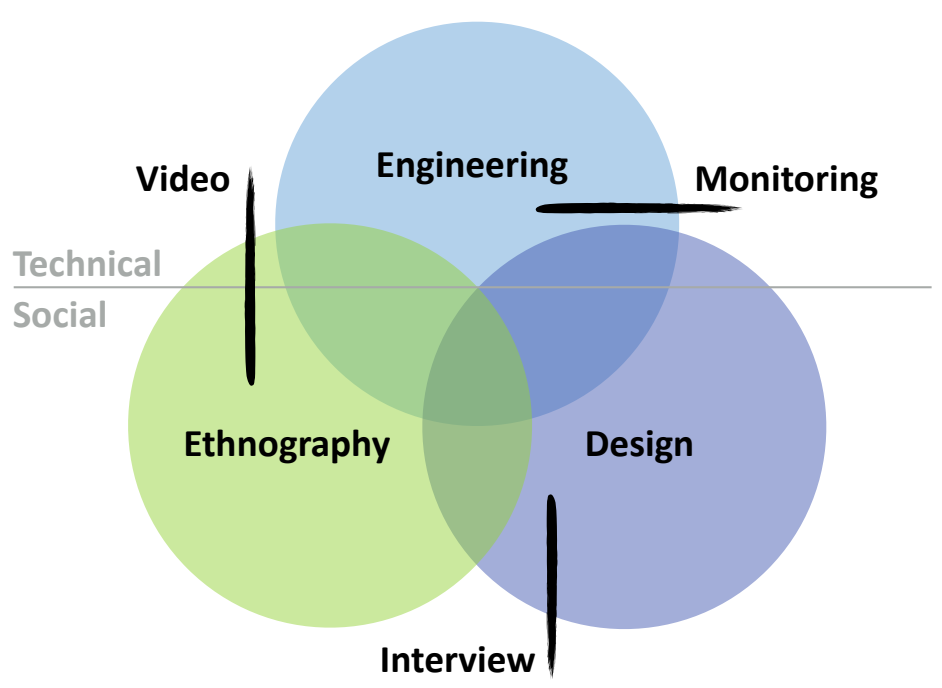

Figure 1 Overview of the relationships between research disciplines and data types

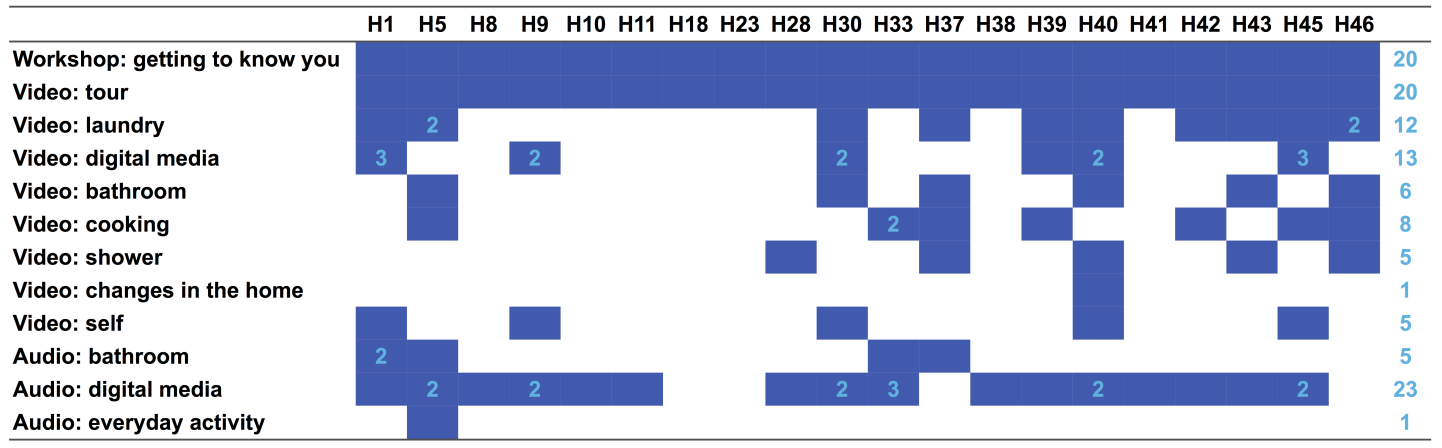

Figure 2 Social data collection activity across the households

investigators, researchers and $\mathrm{PhD}$ students. There were 76 meetings with minutes held over 4 years (approximately once every 2 weeks).

The data used to underpin the analysis on the project was gathered through a combination of high resolution, whole house and appliance energy monitoring (Buswell et al., 2013), video re-enactment activities (Leder Mackley and Pink, 2013) and audio recorded/transcribed interviews and workshop activities (Mitchell et al., 2014). The scale of the data collection exercise is indicated by the following statistics: there were 120 sets of social data collected, an average of 6 per home; and the technical data comprised of a technical survey of the home, a demographic survey of the family and an average of 53 measurement channels per home.

Figure 2 depicts a map of the social data collected across the sample. The Getting-to-Know-You exercise was a 2-3 hour audio recorded workshop involving two researchers and the whole family, aimed at understanding attitudes and routines in the home. The 'Video' exercises were household routines re-enacted by participants (usually one family member) while being video-recorded. In Figure 2, the light blue numbers indicate where more than 


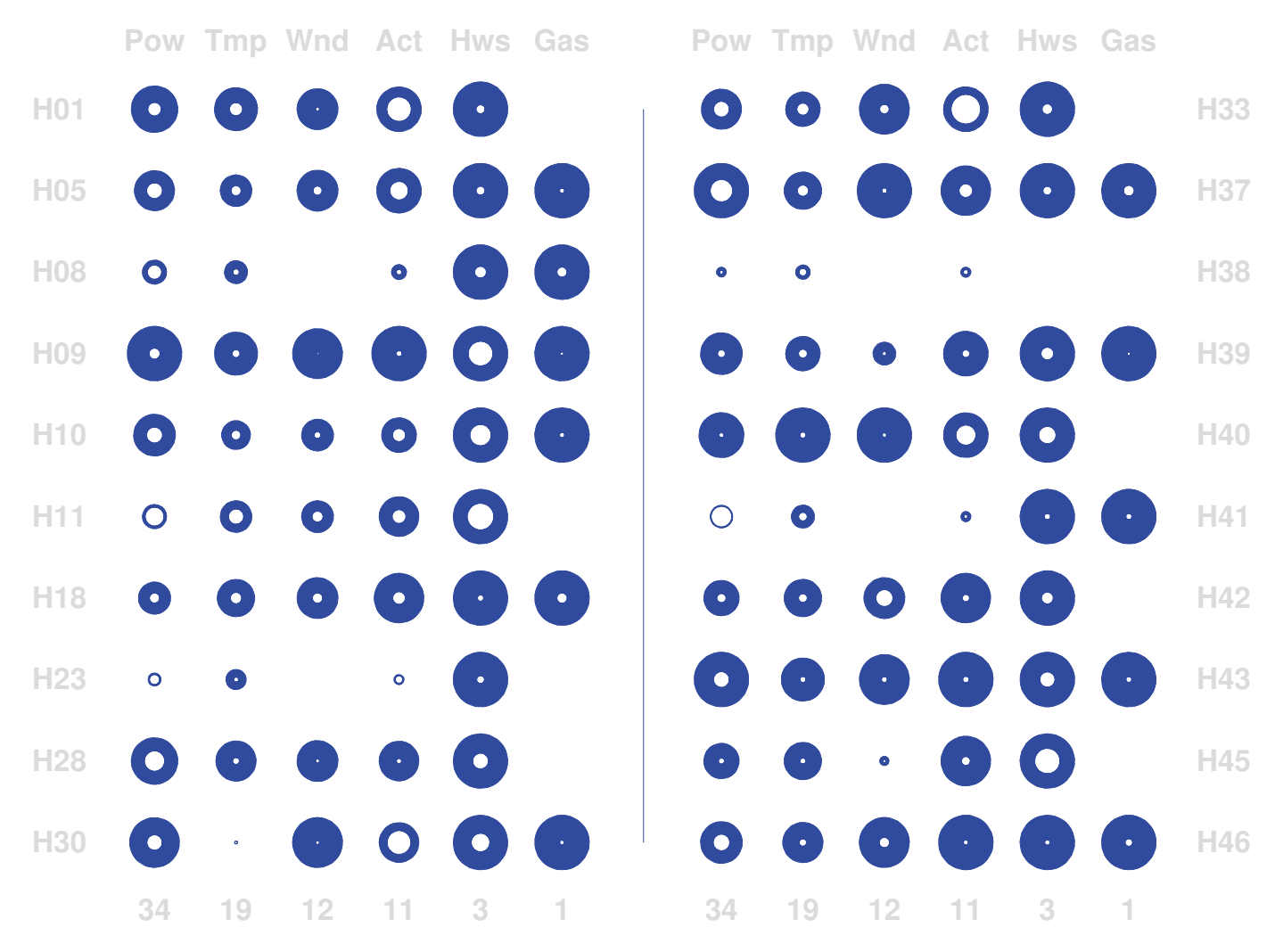

Figure 3 Data availability and relative number of monitoring channels per house

one activity took place, and the column on the far right provide the total number of events for each activity.

Figure 3 depicts the extent of the technical monitoring. All 20 homes are represented in 2 columns of 10 . Sub-columns, represent measurement channels: power (Pow), temperature (Tmp), window and door opening (Wnd), activity or (Passive Infra Red devices; Act), hot water (volume and temperatures) (Hws) and gas flow (Gas). The maximum number of sensors installed in any one house is given along the bottom (repeated on the left and right hand sides), hence the outer diameter of the discs can be compared in each column and used to compare the numbers of devices in each home. Some data is always lost in monitoring schemes and the number of available data is represented by the thickness of the blue disc: a solid blue disk means $100 \%$ of the data is available.

\section{Data sources}

Throughout LEEDR, Microsoft Outlook calendars were maintained for each household. These diary entries were then downloaded into a spreadsheet and each entry systematically encoded by activity type:

- phone conversations and emails between researchers and householders;

- visits to homes for maintenance of monitoring systems;

- visits to homes to accompany contractors carrying out installation work; 
- installation of the power, temperature, window and movement measurement system;

- installation of the gas and hot water measurement system;

- initial visits and surveys;

- initial workshop activities; and,

- the routine re-enactment and interview sessions.

In all, 3000 diary entries were coded over the 4 years of the project so that the frequency and timing of project events that involved the researchers with the participants (the householders) could be identified.

\section{Quantifying research 'power', 'effort' and 'overhead'}

'Research power' describes the Full Time Equivalent (FTE) researcher contracted hours (37.5 hours per week), including both research staff and $\mathrm{PhD}$ students working on the project: note this is not the same as 'research power' used in the UK Research Excellence Framework (REF, 2014).

'Research effort' is defined as the researcher FTE expended on the collection of the data as listed in the previous section. The balance of the research power (available wo/man hours) and the research effort (wo/man hours expended collecting data) indicate the time for all other project, institutional duties and career development activities. The research effort is a useful measure because researchers are contracted to a project and the data is the critical component that underpins its success. Therefore obtaining data must take priority over all other aspects of the project. Quantifying the time spent on data collection allows grounded reflection on the remaining resource available to develop new knowledge by analysing the data.

The duration of events were not recorded in the diary entries, and hence estimates of key operational tasks were developed through consensus based discussions with the researchers involved. Estimates of the time taken for each activity is given in Table 2. Activities are listed on the left hand side, operational logistics such as travel time to homes and preparation time on the right hand side. The two central columns indicate the effort for participants and researchers. Noted in the brackets are the number of households taking part (Participants) and the number of researchers involved (Researchers). With regards to Table 2, the 'Video Tour' was an initial exercise to establish how families make their home 'feel right'. The 'Enuf' event was an intervention installed in homes to help people reduce time spent in the shower. Surveys were used to collect demographic information from family members as well as technical details about the house, its appliances and systems.

The data in Table 2 is given per event and so the effort can be estimated in hours expended by the participants (the 'participant effort') as well as the researchers (the 'research effort'). This effort can be regarded as the 'overhead' that is required in order to create new knowledge when undertaking a project of this type. 
Table 2 Parameters for the effort model

\begin{tabular}{lrrrr}
\hline Activity & $\begin{array}{r}\text { Participants } \\
\text { Hours/ (Number } \\
\text { involved) }\end{array}$ & $\begin{array}{r}\text { Researchers } \\
\text { Hours/ } \\
\text { (Number involved) }\end{array}$ & $\begin{array}{r}\text { Hours } \\
\text { travel } \\
\text { time }\end{array}$ & $\begin{array}{r}\text { Hours } \\
\text { prep. } \\
\text { time }\end{array}$ \\
\hline Initial phone call & $0.5(20)$ & $0.5(1)$ & 0 & 0 \\
Email/Phone contacts & $0.3(20)$ & $0.3(1)$ & 0 & 0.5 \\
\hline Initial visit & $1.5(20)$ & $1.5(2)$ & 1 & 1 \\
Getting-To-Know-You & $2.5(20)$ & $2.5(2)$ & 1 & 6 \\
Video tours & $2(20)$ & $2(1)$ & 1 & 2.5 \\
Video Tour follow-up & $1.5(19)$ & $1.5(1)$ & 1 & 3 \\
Video Practices & $5(11)$ & $5(1)$ & 1 & 1.5 \\
Enuf installation & $0.5(6)$ & $0.5(2)$ & 1 & 0.5 \\
Enuf debrief & $1.5(6)$ & $1.5(2)$ & 1 & 0.5 \\
\hline Technical survey & $1.5(20)$ & $1.5(1)$ & 1 & 1 \\
On-line survey & $1(20)$ & $0(0)$ & 0 & 0.5 \\
Pre-installation works & $1.5(20)$ & $1.5(1)$ & 1 & 3 \\
Maintenance visits & $0.75(20)$ & $0.75(1)$ & 1 & 0.5 \\
Monitoring installation & $8(20)$ & $8(1)$ & 1 & 16 \\
Monitoring decomm. & $8(20)$ & $8(1)$ & 1 & 16 \\
\hline
\end{tabular}

\section{Measuring knowledge generation}

The analysis phase of the research project yields knowledge and in order to investigate the implications of operational issues, knowledge generation must be quantified. There have been numerous indicators of the success of a project identified (Mårtensson, 2016), but in academia, generally this can be measured in terms of published outputs, such as PhD theses, articles or book chapters (Beerkens, 2013; Cummings and Kiesler, 2007). Here conference, journal papers and book chapters are used as a crude but practical metric to indicate the production of knowledge. No further analysis of the quality or contribution of the paper to the field, or to the integration of the disciplinary insights reported is made here.

\section{Results}

Figure 4 presents the research power, effort and publication generation rate over the duration of the LEEDR project. The horizontal axis represents project duration (months) and the vertical axis, researcher time (FTE). The project start date and the planned completion date are noted in red, indicating a six-month project extension period. The bottom dark grey bar indicates the monitoring period from the first installation to the last decommission. The dark blue blocks indicate the engineering research power on the top and the light blue, the combined social sciences and design disciplines on bottom. The darker sections indicate the research power provided by research associates, and the lighter sections indicate that provided by PhD students. 


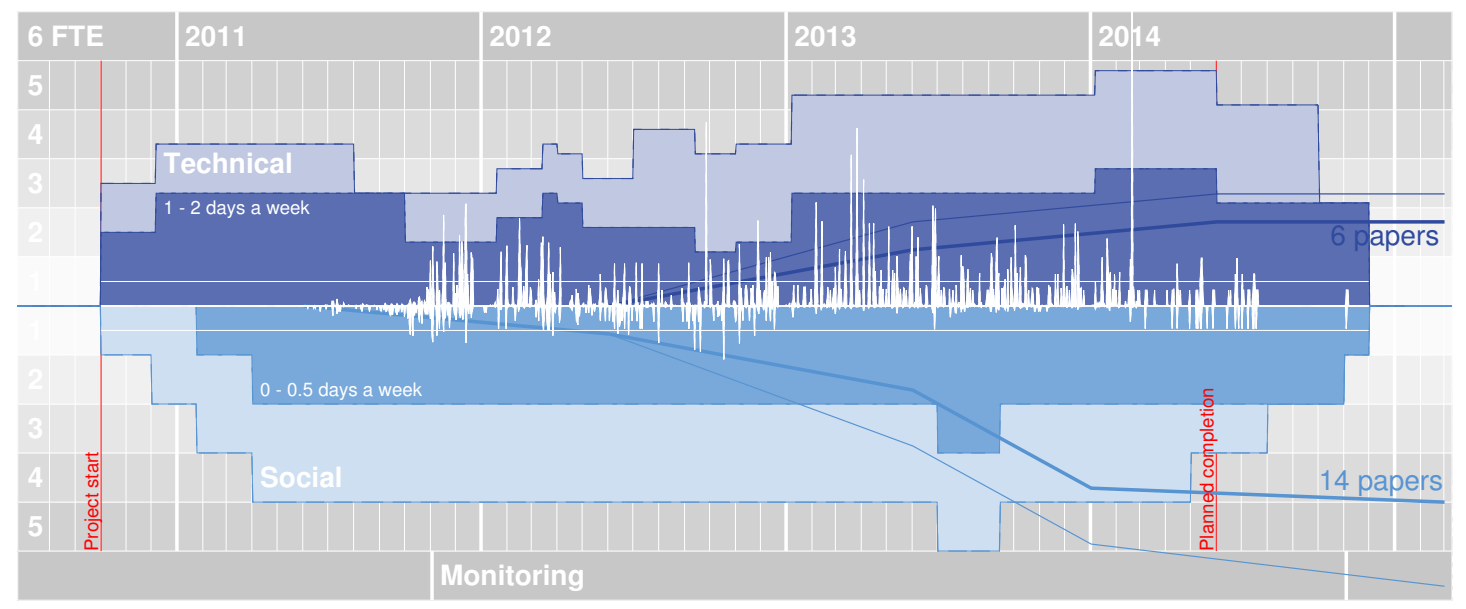

Figure 4 LEEDR project research power, effort and publication generation rate

Difficulties recruiting staff led to the technical team research power fluctuating between mid 2011 and through 2012, largely due to short term contracts required to recruit specific expertise in order to deliver the home monitoring system. The social and technical research power was evenly balanced across the team from 2013 onwards.

The white trace on the plot indicates the time spent by both social and technical teams engaging with householders to gather the data. The two fine white horizontal lines highlight where 0.5 FTE falls. There was a busy period in late 2011 , which is when the households were being brought onto the project. What is notable is the majority of the social data collection was completed towards the end of 2013 and the level of participant engagement subsequently became less intense. In contrast, the effort in the technical data collection continued unabated, mainly due to problem solving, battery changing and other systems maintenance issues. The average time spent by the technical team in the active period between mid 2011 to mid 2014, was 1 - 2 days a week for one researcher (0.2 - 0.4 FTE), and for the social team, up to $1 / 2$ a day a week (0.1 FTE).

Knowledge generation is represented by the 4 lines that progress rightwards on Figure 4. The heavier lines indicate the number of academic silo-based publications arising from each discipline, the finer lines represent the involvement in interdisciplinary publications. The overall number of publications at the end of the LEEDR project were 27, and at 8 FTE equated to 3.4 publications per FTE: in comparison, the REFIT project published 16 publications at 6 FTE, resulting in a very similar 2.7 publications per FTE.

What becomes evident when the rates of data collection are considered is the rapidity that social data can be collected in relation to technical data. Figure 5 depicts data collection rates calculated by cumulative sum of data volume (Gb) produced, normalised by the total for each data stream. The stepping in the social data is due to the discrete nature of the data capture events, whereas the technical data grows at a constant rate, once all measurement channels have been installed. There is some synchronicity in the generation rates of the video and monitoring data, in that they are almost parallel, but the data streams are temporally distant. This can be traced back to two principle reasons: 


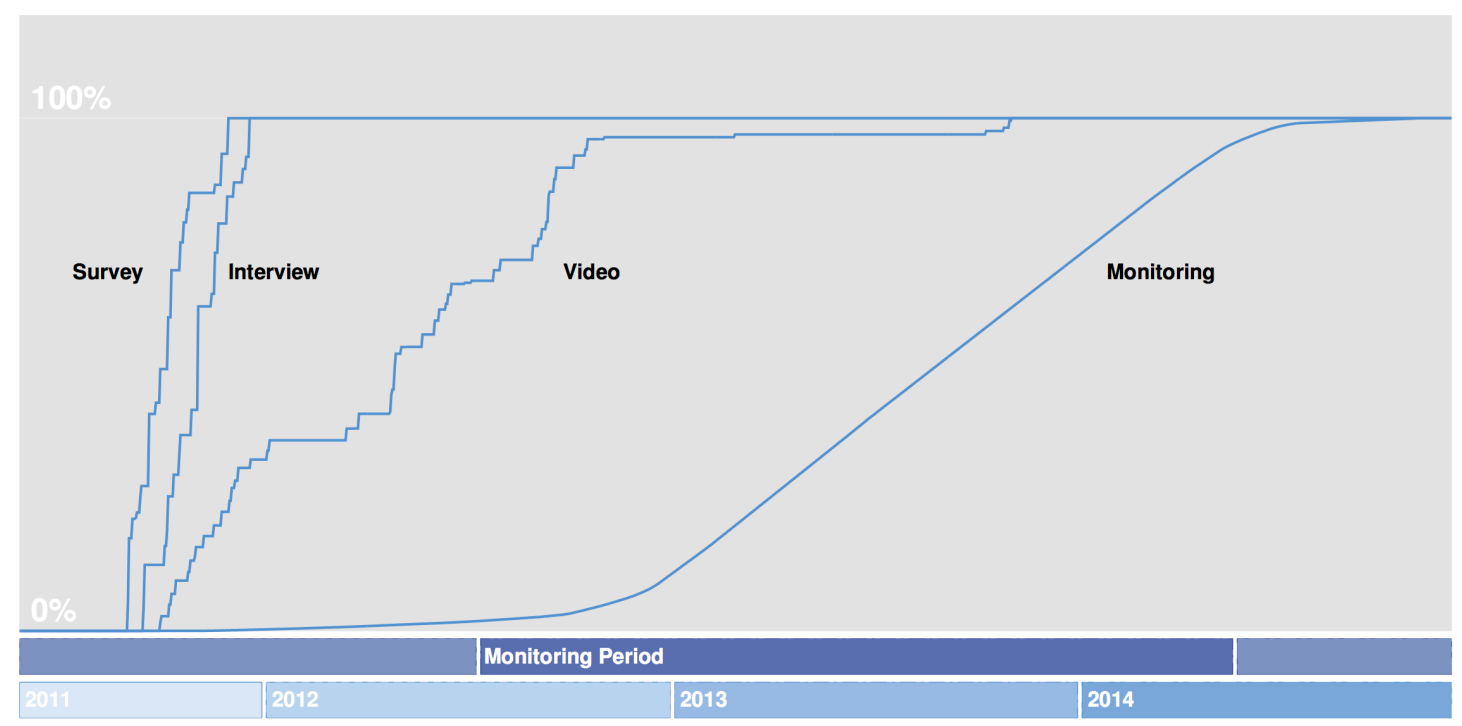

Figure 5 Data generation rates for each data type used on the project

- the initial social data was to be collected before any monitoring was installed for methodological reasons; and

- issues with the monitoring equipment meant only partial installations could be undertaken at first, with the rest installed mid 2012 - early 2013.

This contributed to the social researchers starting to generate knowledge (publications) about 12 months ahead of the technical team.

\section{The participant perspective}

The detailed engagement for one of the more active households ( $\mathrm{H} 40$ ) is illustrated in Figure 6. Each event is represented by a single bar the height of which represents the activity duration. Although the event took place at the 'centre' of the bar, the width is equivalent to 1 week (7 days) on this scale so that a sense of 'contact density' can be gained. The three shades of blue represent phone calls and emails (royal blue), visits to do with monitoring and include installation, maintenance and decommissioning (slate blue) and the other visits associated with the Getting-To-Know-You activity, the Enuf shower and practice studies (pale blue). After the decommissioning and removal of the monitoring equipment there was little interaction with the households until the end of the project when there was a householder feedback day which involved two hours of their time and 10 of the research staff.

The density of activities placed a burden on the participants, but to counter this, it also helped maintain an active interest in the project after the social data had been collected. Across the households the average number of project contact events and the hours of effort by participants and researchers is given in Table 3. Over about three years there were on average 109 contact events: ranging between 60 and 205 from the least to the most highly engaged households respectively. The average of researcher-hours per house was found to be 429 hours (range: 235 hours - 734 hours) but significantly, the household time spent 


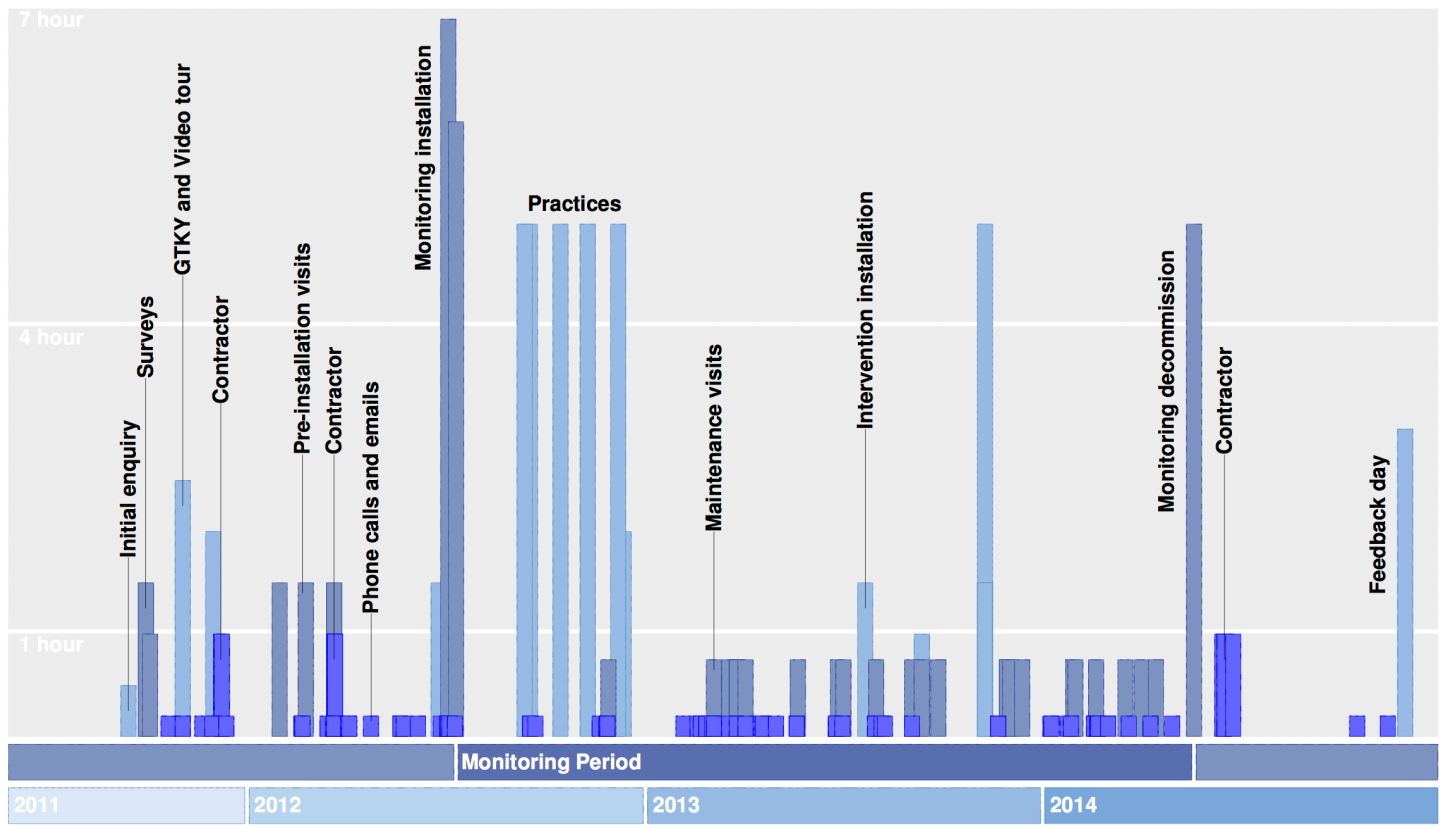

Figure 6 Householder effort in terms of hours per visit for one of the busier homes (H40)

Table 3 Average number of householder/researcher interaction events (-) and the average involvement time (hours) per house required to collect data

\begin{tabular}{lrrr}
\hline & Contact & Observation & Monitoring \\
\hline Events & 72 & 11 & 26 \\
Household time & 72 & 24 & 121 \\
Researcher time & 131 & 114 & 184 \\
\hline
\end{tabular}

engaged with the project on average was 217 hours per house (range: 103 hours - 417 hours): equivalent to 27 working days for one family member.

\section{Pre-processing data after collection}

Both social and technical data require some pre-processing prior to analysis, and this varies depending on data type. Typical requirements are:

- audio recorded interviews must be transcribed, encoded and anonymized;

- videoed re-enactment required the footage to be catalogued, insights cross referenced with a time stamp in order to develop narratives; and,

- monitoring data requires filtering, time stamp alignment, sample interval alignment, rejection of data and fault finding, and dealing with missing data.

Technical data in particular is often problematic because there is less control over the collection process than with social techniques. It is affected by: internet performance; third party servers; equipment failure; and human interference. 


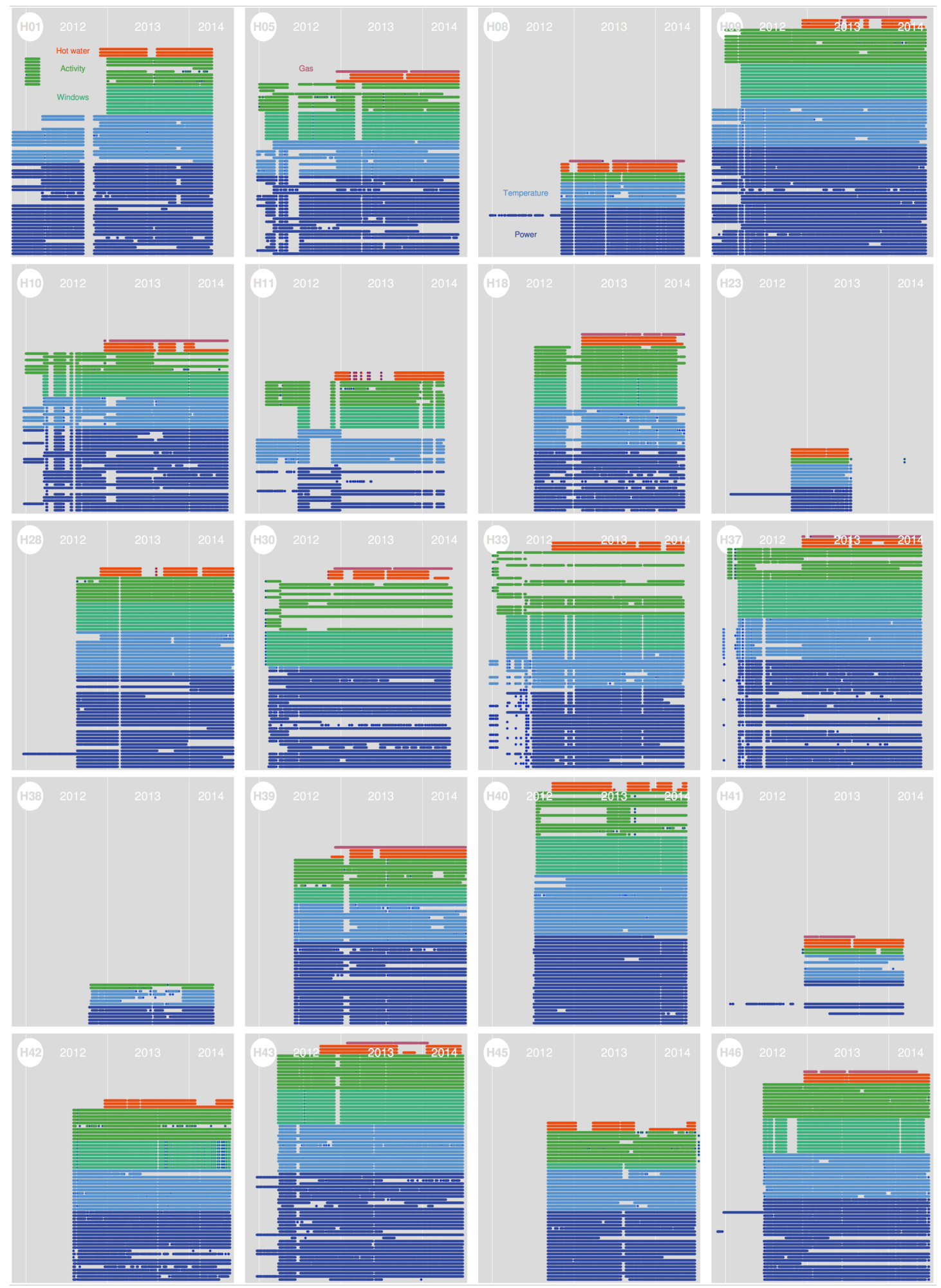

Figure 7 The quality and availability of monitoring data collected from each home: the dark blue represents power measurements, light blue, temperatures, lime green, window and door opening, dark green, PIR activity, orange, hot water and dark red, gas

Figure 7 depicts all technical data monitored during LEEDR. Each grey block in the figure represents a house, each line a measurement channel, and each dot represents a complete set of 24 hours of available data. The red lines at the top of each depict the hot water and gas measurements where monitored. What is 
evident is the patchy nature of the data, the problems with monitoring channels being altered when faulty devices are found, all of which hampers the analysis through much greater time required to compensate for missing data.

What is not included in the white researcher-time bars plotted in Figure 4, is the effort from two of the investigators (academics), one of whom developed the code for the operation of the gas monitoring system and the other that carried out the pre-processing and error checking on all the monitored data. This amounted to an additional a day a week for each task (0.4 FTE in total) for 12 months of the project (mid 2012 into late 2013).

\section{Cost of data collection}

Reported costs for in home energy studies have been suggested by Palmer et al. (2015) and estimated by Cooper et al. (2014), who acknowledge the lack of information available and hence the uncertainty in estimating costs. The comparison of their work to the monitored costs incurred on the LEEDR project is given in Tables 4 and 5 .

Palmer et al. present costs for a lightweight monitoring installation designed to run alongside existing national surveys (such as DCLG, 2015), installing about 45 additional measurement channels, over and above pre-installed smart meters measuring gas and electricity. Their costs are given over three years to compare to the Cooper et al. study. The Cooper et al. study describes a multi level approach to survey work, monitoring and other social insights. Each of the three levels increases in complexity, and the Palmer et al. estimates compare favourably with the 'Level 2' study costs suggested by Cooper et al., which also assumes around 5 devises on top of pre-installed smart meters. The estimates $£ 1,216$ and $£ 1,240$ per house from the Firth and Palmer and Cooper et al. study respectively (Table 4).

The upper end of the Cooper et al. study approaches the study undertaken on LEEDR, but with about half the intensity of monitoring and with less social science engagement. The survey design in the Cooper et al. study is assumed to be complete and hence not factored into the costs and also utilises off-the-shelf monitoring equipment, with no hot water monitoring and (relatively to LEEDR) low resolution gas and electricity measurement through pre-installed smart meters. Table 5 presents the costs. LEEDR costs are based over a 4 year project, where about a year is planning followed by 2 years of monitoring. The Cooper at al. study is designed for Level 3 to be for a maximum of 1 year, and so it has been assumed that were this to be extended to 2 years, that fixed costs would double since this contains the management and data processing, although it is noted that some additional trouble shooting visits have been included in the labour portion of the marginal costs. Cooper et al. estimate $£ 21,590$ per house for 2 years of data collection whereas the LEEDR costs were $£ 46,245$ per house. The LEEDR calculations are based on Full Economic Costing (FEC): 42 weeks/year; 37.5 hours/week; a manager cost of $£ 135,000$ per year ( $£ 85.71$ per hour); and a 
Table 4 Cost comparison between Palmer et al. (2013) and Cooper et al. (2014) for lightweight monitoring for 3 years of up to 5 measurement devices on top of pre-installed smart meters

\begin{tabular}{|c|c|c|c|c|}
\hline Description & Palmer et al. & Cost & Cooper et al.: level 2 & Cost \\
\hline $\begin{array}{l}\text { Management overhead } \\
\text { (fixed costs in Cooper et } \\
\text { al.) }\end{array}$ & $100,000 / 1,000$ homes & 100 & $\begin{array}{l}\text { Level } 1 \text { costs }= \\
(1,000,000 / 10,000)+ \\
\text { Level } 2 \text { costs }= \\
(800,000 / 8,000)\end{array}$ & 200 \\
\hline $\begin{array}{l}\text { Research method } \\
\text { development and } \\
\text { planning overhead }\end{array}$ & $\mathrm{N} / \mathrm{A}$ & 0 & $\mathrm{~N} / \mathrm{A}$ & 0 \\
\hline Subtotal & & $£ 100$ & & $£ 200$ \\
\hline $\begin{array}{l}\text { Data collection for } \\
\text { project period (marginal } \\
\text { labour costs in Cooper et } \\
\text { al.) }\end{array}$ & $\begin{array}{l}232,000 \text { per year } \\
\text { divided by } 1,000 \\
\text { homes by } 3 \text { years }\end{array}$ & 696 & Level $1+2=110+260$ & 370 \\
\hline Subtotal & & $£ 696$ & & $£ 370$ \\
\hline Pre-processing data & Included & 0 & Included & 0 \\
\hline \multirow[t]{4}{*}{$\begin{array}{l}\text { Equipment cost } \\
\text { (marginal materials } \\
\text { costs and in Cooper et al.) }\end{array}$} & $\begin{array}{l}420,000 / 1,000 \\
\text { houses }\end{array}$ & 420 & Level $1+2=20+500$ & 520 \\
\hline & $\begin{array}{l}\text { Gas and electricity } \\
\text { measured through } \\
\text { smart meter }\end{array}$ & 0 & $\begin{array}{l}\text { Gas and electricity } \\
\text { measured through smart } \\
\text { meter }\end{array}$ & 0 \\
\hline & $\begin{array}{l}\text { Hot water not } \\
\text { measured }\end{array}$ & 0 & Hot water not measured & 0 \\
\hline & & 0 & Included & 0 \\
\hline Incentives & Not required & 0 & Level $1+2=0+150$ & 150 \\
\hline Subtotal & & $£ 420$ & & $£ 670$ \\
\hline Total cost per house & & $£ 1,216$ & & $£ 1,240$ \\
\hline
\end{tabular}

researcher cost of $£ 90,000$ per year ( $£ 56.25$ per hour). The cost implications of the key differences between the studies are:

- if the LEEDR research design had already been developed, then the figure would reduce by $£ 10,125$ per house; and,

- the social science component of the LEEDR data collection is about 25\%, equating to $£ 6,034$ per house, and so if it was assumed that a simpler and more mature measurement system was implemented, the technical support effort might reduce by a factor of 2 , reducing the figure of $£ 24,131$ to $£ 15,082$ per house. 
Table 5 Cost comparison between Cooper et al. (2014) and LEEDR for detailled monitoring for 2 years of 20-50 devices with additional observations and/or tests, depending on the study

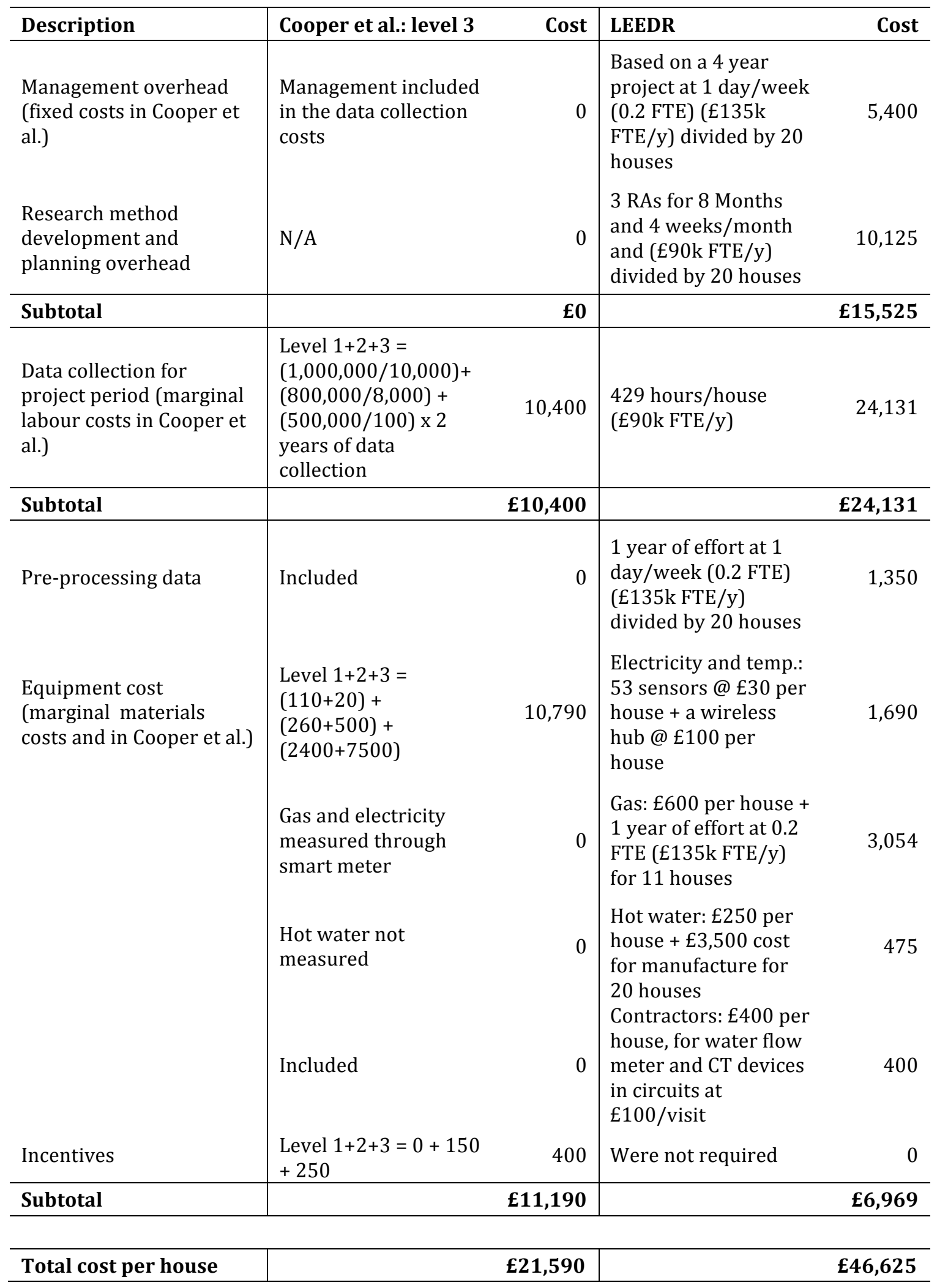

This would bring the LEEDR estimates down from $£ 46,245$ to $£ 27,251$ : $26 \%$ larger than the Cooper et al. estimates. The difference of $£ 5,661$ per house will be a combination of uncertainty in the management overhead and instrumentation 
costs. There will also be some time lost in the development of the measurement equipment, which would increase the estimates for LEEDR. However, if the Cooper et al. costs have been underestimated at all, the figures would suggest that this is in the maintenance of the data collection for which, even when the above reductions have been factored in there remains a $£ 4,682$ difference per house.

\section{Discussion}

The effort collecting multidisciplinary data has been quantified for the case study and was found to be about 2 days ( 0.4 FTE) of researcher-time a week for the duration both the social and technical data collection and an additional 1 day (0.2 FTE) per week in pre-processing the technical data over the first 12 month period of data collection. The REFIT project also had investigators from user centred design, social science and engineering and focused on the impact of smart home devices on energy consumption, based on a sample of 20 homes. The social team made 150 visits to homes to collect data and a long term monitoring scheme of about 60 measurements per home was installed over a 2.5 year period. This team self-reported an overhead of 0.4 FTE to 0.6 FTE of engagement with homes, similar to that quantified here.

\section{Operational issues encountered}

The collection of the technical data was effected by 2 issues. The first was the lack of technical support from the partner supplying the majority of the monitoring equipment that led to time lost configuring the systems correctly (observed by Newell and Swan, 2000). The partner had undergone significant changes in the year between the proposal being written and the start of the project. It had doubled in size, was negotiating a take over deal and was struggling to keep up the demand for its product to its customers that affected their capacity to support the project. The second was the technical challenge of developing specialist measurement equipment in-house which involved deadends and wasted resource followed by difficulty bringing in the right expertise to resolve the problems and facilitate the manufacture of the solutions. Lower resolution, off-the-shelf equipment might have proved to be more robust and may have reduced the research effort.

These issues compressed the time available to carry out adequate field testing which meant that some problems were not identified until the devices were in operation which then needed to be managed to the end of the project. Clock synchronisation between monitoring systems is one example that was challenging to handle, particularly with non-internet connected devices and can have repercussions for downstream analysis. These issues generated a delay in the production of the technical data, and indeed drew the focus of the technical team, which very much reduced the capacity to make meaningful in-roads to the analysis. 


\section{Keeping it together}

To some extent some fragmentation observed by Newell and Swan (2000), had begun to occur between the disciplines as researchers focused on developing their discipline specific methods in the run up to the recruitment phase which reflected issues with the management of different research disciplines reported by Whitley (1984). This fragmentation may have been exacerbated because of the decision by the investigators to house their researchers within individual schools, rather than having them co-located as originally planned: i.e. implementing the rule of thumb that co-workers should be no more than 30 meters apart (Allen, 1977 and Kraut, et al., 1990). Many sound reasons where tabled for this including: the development of a researcher in their specialist field, the support offered by other staff working in similar epistemological positions, networking and building personal relations with those people, opportunities for developing other skills, such as teaching as well as the greater ease of day-to-day line management issues.

Newell and Swan (2000) studied a multi-institutional project that was geographically dispersed and yet many of the observations made in their study were true of the single institutional project reported here, for example:

'The team did have fairly regular face-to-face meetings, although these were never as frequent as originally intended because of the difficulties of actually finding dates on which all the PIs could attend.' (Newell and Swan, 2000, p1309)

Although this was mitigated to an extent by virtue of being a single institution project, which meant that the PI could meet with individuals and attempt to resolve issues and conflicts one-to-one, when round table meetings could not be organized.

'[researchers were]...left to 'make sense' of their role and their relationships with each other by themselves' (Newell and Swan, 2000, p1310)

Also echoed in the experiences of the LEEDR team, but again the frequency of the meetings meant that these issues were identified and dealt with swiftly as they emerged.

\section{External constraints}

Observations by Newell and Swan (2000), König et al. (2013) and Cummings and Kiesler (2007), would suggest that to do multidisciplinary work well you need to: pick a team with specific characteristics; involve all members to ensure the best combination of social and technical working; co-locate all members; and have a clear management structure. However these are somewhat shaped by funding and institutional structures, expectations, management structure and approach (Beerkens, 2013), all of which affect: knowledge/output production (Mårtensson,2016; Cummings and Kiesler, 2007) and career progression (Millar, 2013). Practically: staff retention and commitment to support the careers and 
training of staff on temporary contracts and the desire to complete old projects while starting new ones means often that 'special' selection processes are not practicable; co-location can be problematic, particularly when there are space and specialist equipment constraints; and academic management is inherently conflicted with line management falling across departments and schools, not dedicated to the project. The problem is often therefore finding the ideal mix of technical and social skills in all team members, which reinforces the sense that the 'success' of research projects cannot be guaranteed (Atkinson, 1999; de Wit, 1988).

\section{Data gathering and knowledge generation}

The rates at which data is collected can be similar for both social and technical data (Figure 5). The time frame over which the data by either social or technical data is collected is variable depending on the research question and can span significant amounts of time in both cases. The difference between them is that social data tends to be collected through intense discrete activities, measured in hours, whereas technical data tends to be continuous time series data. In reference to the methods used on LEEDR, the quality of the social data is assessed during the collection/generation process since the researcher is present in real time. Insights can be generated after each event and continue in parallel with the gathering process (at least in principle). To an extent this is true of technical data, but in building energy monitoring, season is often a significant factor in analysis and hence useful insights tend to be generated after large amounts of time have lapsed (months and years). This is coupled with the problems of 'eyeballing' each of the discrete measurement channels on their own and in multiple combinations to ascertain value therein, or (commonly) to identify errors in order to reject data from subsequent analysis.

The sequencing of both data collection types is also important and determined by the methodological standpoint of the research team. LEEDR established that the initial interviews must be carried out prior to technology entering the home to avoid any distortion of responses in the social data collection. In contrast, Love's work reported in Love and Cooper (2015), described social data that was gathered some time after the technical data systems were installed in homes. What is important is that insights from both data streams emerge at the right time to allow them to intertwine, but this can be, and often is affected by operational constraints that can reinforce the characteristic differences between the data types.

For interdisciplinary insights to emerge, Shahin et al. (2014) suggested there needed to be a clear vision of the research disciplines that identified interfaces. Love and Cooper (2015) make the case for ensuring that the development of a truly socio-technical research design is also critical to success, and highlights problems with spatio-temporal alignment of data types. To add to this debate, the observations from this work tend to suggest that although interdisciplinary working is envisioned, pragmatism silos the data gathering process. Knowledge sharing, therefore will tend to take place after mono-disciplinary insights have 
been generated. There must be, however, sufficient time to allow those insights to be questioned so perspectives can mix. The challenge is how to plan and manage the project so that the individuals and the context of their research data come together at the most appropriate time.

Operational constraints make this a small target to hit and therefore leads to fragility in the inter-disciplinary process, which can be disrupted by: in appropriate programming and planning; unforeseen problems affecting one or more data streams, causing it to become out of step with the others; poor communication and lack of trust between investigators and researchers; funding and institutional constraints in appointing staff, as observed by others (Campbell, 2005; Jacobs and Frickel, 2009; Younglove-Webb et al., 1999; Jacobs and Frickel, 2009; Golde and Gallagher, 1999; Metzger and Zare, 1999; Lowe and Phillipson, 2009; Mallaband and Haines, 2014; Waterton et al., 2006; Bracken and Oughton, 2006; Saddon, 2015).

The way a project arrives at new insights is more complicated than implied by Figure 1. Inspired by the models and discussion presented by Linder and Wald (2011), Fong (2003) and Newell and Swan (2000), and drawn from the analysis undertaken in this work, Figure 8 presents a representation of the process and fragility of generating interdisciplinary knowledge.

Interdisciplinary insights can be considered to be a ball on top of a stool, where each leg (three in this case) represents a data stream generated by a single discipline. The horizontal struts are the opportunities to bring the insights from individual perspectives together, after which there is a reassessment of the knowledge/insights in both research streams. Time is represented by the length of each leg and hence when everything synchronises, the seat is flat and the ball is centred between the disciplines. This represents the ideal process, envisioned during planning.

On some projects (top right) there is no coming together of the disciplines and hence no interdisciplinary insights are generated (although, of course, there could be significant mono-disciplinary work delivered).

On LEEDR (bottom left), the delays in the technical monitoring system meant that the 'time-to-insights' was longer than for the two social disciplines (user centred design and ethnography) and hence they were able to synchronise and deliver more interdisciplinary insights, biasing the project outcomes (at the project completion date).

Perhaps a more realistic representation of how interdisciplinary knowledge might be created happens over a longer time frame than the project itself and is offered in the bottom left diagram. Here the insights gained tend to carry over to other projects (Linder and Wald, 2011) and continue to develop through follow on projects and so while those three way insights may not be gained in the course of the original project, they may well be delivered eventually, providing time and funding have been available to continue and allow the multidisciplinary discourse to mature. 

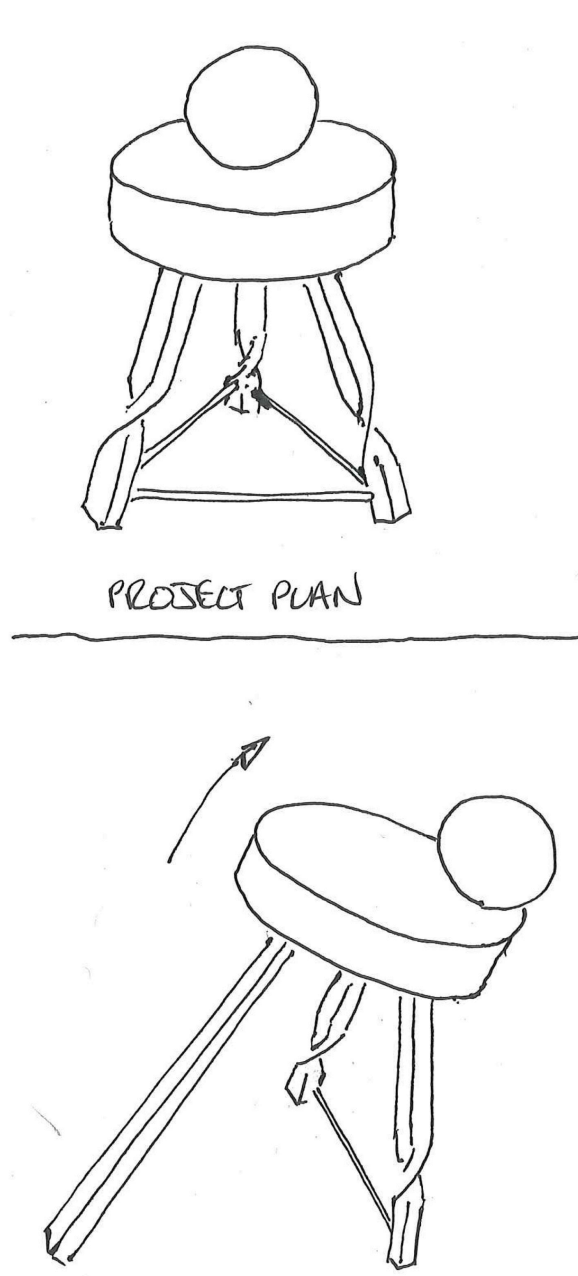

BIAS INSIGLTSS

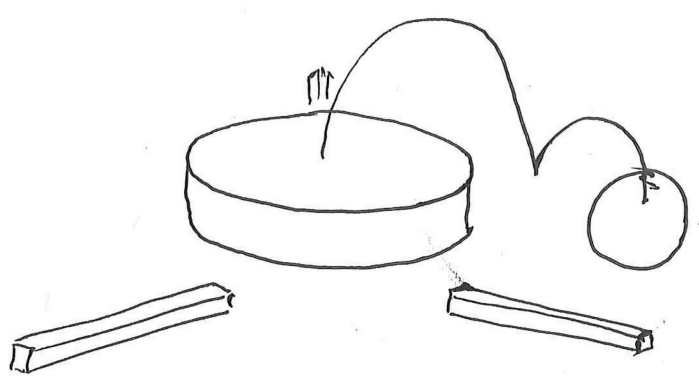

NO COMMUNICATION

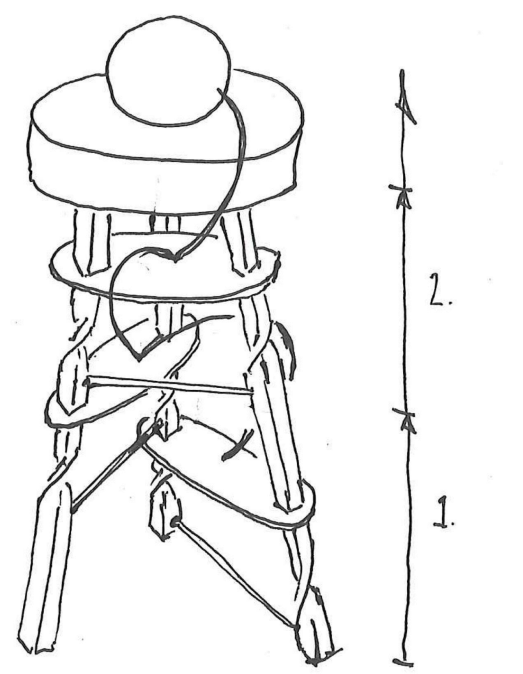

MORE REALISTK.

Figure $8 \mathrm{~A}$ model of the operational process of generating interdisciplinary insights developed from the case study

Drawing back from the individual project, the model tends to suggest that if inter-disciplinary research is a real goal, then it requires longer term planning, both at an investigator level in terms of career choice, but also through funding bodies by enabling successive calls to be sufficiently aligned as to promote the retention of skills in order to develop insights.

\section{Conclusions}

Research to inform strategies and interventions for behaviour change and technology innovation will underpin the necessary demand reductions required by the 2050 carbon targets. Complex data sets are beginning to emerge from research projects that are engaged in understanding more about people and their interaction with, systems, buildings and technology. The effort involved in 
data collection (before any analysis has taken place) has been quantified for the first time by this work and a number of metrics have been established that can be utilised when planning future work:

- research hours to collect data, 429 hours per house;

- participant engagement time, 217 hours per house;

- indicative costs for rolling out detailed socio-technical investigation with established, reliable methods, $£ 22,000$ to $£ 27,000$ hours per house;

- indicative costs for rolling out detailed socio-technical investigation with new untested methods, is in the region of $£ 46,000$ hours per house; and,

- publication expectation is about 3 publications per FTE during the lifetime of a 3-4 year project that includes 2 years of data collection.

The analysis demonstrates that when planning future projects, the tendency can be to underestimate the overhead in maintaining technical data collection systems. Technical data collection is intrinsically more sensitive to disruption than social data collection because it needs to be collected over a longer period of time and has more dependencies that are out of the control of the project team. The likelihood is, that it will be the technical data stream that will run out of sync with the social data.

A suggestion made on the basis of the work undertaken here is that the social research should start after monitoring systems have been installed for at least 6 months, although this may be not be acceptable for social science teams concerned about how the presence of equipment in the home may impact upon behaviour.

A model of knowledge generation was proposed that illustrates the fragility of generating interdisciplinary insights from complicated project, however projects can minimise this fragility by careful management thinking carefully through issues around:

- co-location of the project team;

- active promotion of the value of multidisciplinary outcomes;

- generation of space for knowledge to develop;

- creating opportunities for disciplines to intertwine;

- encouraging social and technical trust to develop across team members of different disciplines;

- clear management and goal setting; and,

- appropriate planning and risk management.

One the issue of co-location, having a team at one institution on LEEDR had a positive impact on social and technical trust developing between team members, a grander sense of 'the project' and regular opportunity to engage across disciplinary boundaries: all of which are much harder to achieve with geographically disperse teams.

The model of knowledge generation also suggests that insights will continue to emerge beyond the project, possibly 3-10 years after the original proposal is 
written. Academic research projects must also contend with a rapidly changing context which is out pacing research (Summerfield and Lowe, 2012; Winskel et al., 2015). It is better, therefore to plan follow on projects designed to make use of the data and allow researchers to remain as a team, which will help reduce fragmentation of knowledge.

A significant legacy of these multi-disciplinary projects is the production of data sets that observe the same subjects using different lenses. Allowing wider access increases the utility of the data, hence ensuring adequate consent from participants is gained should be recognised as a critical factor in future projects. If consent is carefully woven into the research methodology early in the project participants may well agree to the release of video footage that cannot be completely anonymized; but if carried out poorly, may mean that not even anonymized numerical data can be distributed outside the project, which would be a significant waste of effort.

\section{Acknowledgements}

This paper is an output from the LEEDR: Low Effort Energy Demand Reduction project (Grant number, EP/I000267/1), funded through the RCUKs, digital Economy and Energy programmes' TEDDI initiative. The authors would like to acknowledge the support of colleagues in TEDDINET (EP/L013681/1) and in particular Steven Firth, David Shipworth and Adam Cooper for their assistance with the REFIT and project costing data used in the paper.

\section{References}

Atkinson, R. (1999). Project management: cost, time and quality, two best guesses and a phenomenon, its time to accept other success criteria. International journal of project management, 17(6), 337-342.

Beerkens, M. (2013). Facts and fads in academic research management: The effect of management practices on research productivity in Australia. Research Policy, 42(9), 1679-1693.

Berker, T., \& Bharathi, K. (2012). Energy and buildings research: challenges from the new production of knowledge. Building Research \& Information, 40(4), 473480.

BIS (2014). THE ALLOCATION OF SCIENCE AND RESEARCH FUNDING 2015/16. Department for Business Innovation and Skills. Assessed online (9/3/16): https://www.gov.uk/government/uploads/system/uploads/attachment_data/fi le/332767/bis-14-750-science-research-funding-allocations-2015-2016corrected.pdf 
Bracken, L. J. \& Oughton, E. A. (2006). what do you mean? the importance of language in developing interdisciplinary research. Transactions of the Institute of British Geographers, 31, 371382. doi: 10.1111/j.1475-5661.2006.00218.x

Brook, M., Eden, D., Ferris, T., Graillat, C., Lam, H., Lerman, S. Menten, R., G., Pennington, W., Regnier., J., Roberts, K. and Wu. J. (2012). COMPREHENSIVE ENERGY EFFICIENCY PROGRAM FOR EXISTING BUILDINGS SCOPING REPORT. California Energy Commission. Assessed online 7/3/16: http://www.energy.ca.gov/2012publications/CEC-400-2012-015/CEC-4002012-015.pdf

Buswell, R. A., Marini, D., Webb, L. H. \& Thomson, M. (2013). Determining heat use in residential buildings using high resolution gas and domestic hot water monitoring. In the proceedings of the 13th International conference on Building Simulation, 25-28 August 2013, Chambery, France. Retrieved from https://dspace.lboro.ac.uk/dspace-jspui/handle/2134/13146

California Energy Commission (2015). Existing Buildings Energy Efficiency Action Plan . September 2015. California Energy Commission. Assessed online: 7/3/17: http://docketpublic.energy.ca.gov/PublicDocuments/15-IEPR05/TN206015_20150904T153548_Existing_Buildings_Energy_Efficiency_Action_ Plan.pdf

Campbell, L. M. (2005). Overcoming obstacles to interdisciplinary research. Conservation Biology, 574-577. doi: 10.1111/j.1523-1739.2005.00058.x

CCC (2015). The Fifth Carbon Budget: The next step towards a low-carbon economy, November 2015. Committee on Climate Change: Accessed online (27/2/16): https://www.theccc.org.uk/publications/

Cooper, A., Shipworth, D. and Humphrey, A. (2014). UK Energy Lab: A feasibility study for a longitudinal, nationally representative, sociotechnical, survey of energy use Final Report. Centre of Energy Epidemiology, UCL and NatCen.

Cummings, J. N., \& Kiesler, S. (2007). Coordination costs and project outcomes in multi-university collaborations. Research Policy, 36(10), 1620-1634.

DCLG, (2015) .'English Housing Survey HOUSEHOLDS 2013-14'. Department for Communities and Local Government.

DECC, (2014). 'Developing DECC's Evidence Base '. Department of Energy and Climate Change.

De Wit, A. (1988). Measurement of project success. International journal of project management, 6(3), 164-170.

Dvir, D., Raz, T., \& Shenhar, A. J. (2003). An empirical analysis of the relationship between project planning and project success. International Journal of Project Management, 21(2), 89-95. 
Energy Efficiency Plan (2011). COMMUNICATION FROM THE COMMISSION TO THE EUROPEAN PARLIAMENT, THE COUNCIL, THE EUROPEAN ECONOMIC AND SOCIAL COMMITTEE AND THE COMMITTEE OF THE REGIONS Energy Efficiency Plan 2011. European Commission.

EPBD (2010). DIRECTIVE 2010/31/EU OF THE EUROPEAN PARLIAMENT AND OF THE COUNCIL of 19 May 2010 on the energy performance of buildings. European Commission. Assessed online on 7/3/16: http://eurlex.europa.eu/legal-content/EN/ALL/;ELX_SESSIONID= FZMjThLLzfxmmMCQGp2Y1s2d3TjwtD8QS3pqdkhXZbwqGwlgY9KN!20646514 24?uri=CELEX:32010L0031

European Commission (2015). Guidance for evaluators of horizon 2020 proposals, version 1.1 of 26 September 2014. Technical report, European Commission.

ETI, (2015). Smart Systems and Heat : Decarbonising Heat for UK Homes. Energy Technologies Institute LLP. Accessed on Line 7/3/16: http://www.eti.co.uk/wp-content/uploads/2015/03/Smart-Systems-and-HeatDecarbonising-Heat-for-UK-Homes-.pdf.

Fong, P. S. (2003). Knowledge creation in multidisciplinary project teams: an empirical study of the processes and their dynamic interrelationships. International Journal of Project Management, 21(7), 479-486.

Golde, C. M. \& Gallagher, H. A. (1999). The challenges of conducting interdisciplinary research in traditional doctoral programs. Ecosystems 2(4), 281-285. doi: 10.1007/s100219900076

Hanna, R., Gross, R., Speirs, J. Heptonstall, P. and Gambhir, A. (2015). UKERC Technology and Policy Assessment Innovation timelines from invention to maturity: A rapid review of the evidence on the time taken for new technologies to reach widespread commercialization. Assessed online (27/2/16): http://www.ukerc.ac.uk/programmes/technology-and-policyassessment/innovation-timelines-from-invention-to-maturity-a-review-of-theevidence-on-the-time-taken-for-new-technologies-to-reach-widespreadcommercialisation.html

Hautala, J., \& Jauhiainen, J. S. (2014). Spatio-temporal processes of knowledge creation. Research Policy, 43(4), 655-668.

Hazas, M., Friday, A. \& Scott, J. (2011). Look back before leaping forward: Four decades of domestic energy inquiry. IEEE; Pervasize Computing 11, 1536-1268. doi: 10.1109/MPRV.2010.89

Hessels, L. K., \& Van Lente, H. (2008). Re-thinking new knowledge production: A literature review and a research agenda. Research policy, 37(4), 740-760. 
Huang, J. C., \& Newell, S. (2003). Knowledge integration processes and dynamics within the context of cross-functional projects. International journal of project management, 21(3), 167-176.

Hunter, E. M., Perry, S. J., \& Currall, S. C. (2011). Inside multi-disciplinary science and engineering research centers: The impact of organizational climate on invention disclosures and patents. Research Policy, 40(9), 1226-1239.

Ika, L. A. (2009). Project success as a topic in project management journals. Project Management Journal, 40(4), 6-19.

Jacobs, J., A. \& Frickel, S. (2009). Interdisciplinarity: A critical assessment. Annual Review of Sociology, 35: 43-65. doi: 10.1146/annurev-soc-070308115954

König, B., Diehl, K., Tscherning, K., \& Helming, K. (2013). A framework for structuring interdisciplinary research management. Research Policy, 42(1), 261272.

Lander, B. (2016). Boundary-spanning in academic healthcare organisations. Research Policy. (In press).

Leder Mackley, K. \& S. Pink (2013). From emplaced knowing to interdisciplinary knowledge: sensory ethnography in energy research. Senses and Society 8(3), 335-353. doi:10.2752/174589313X13712175020596

LCICG. (2014). 'Coordinating Low Carbon Technology Innovation Support The LCICG's Strategic Framework'. Low Carbon Innovation Coordination Group.

Lindner, F., \& Wald, A. (2011). Success factors of knowledge management in temporary organizations. International Journal of project management, 29(7), 877-888.

Lomas, K. J. (2010). Carbon reduction in existing buildings: a transdisciplinary approach. Building Research \& Information 28(1), 1-11, doi:10.1080/09613210903350937

Love, J. \& C. G. Cooper, A (2015). From social and technical to socio-technical: Designing integrated research on domestic energy use. Indoor and Built Environment 0(0), 1-13. doi: 10.1177/1420326X15601722

Lowe, P. \& J. Phillipson (2009). Barriers to research collaboration across disciplines: scientific paradigms and institutional practices. Environment and planning. 41(5), 1171. doi:10.1068/a4175

Mallaband, B. \& V. Haines (2014, September 13th-17th, SEATTLE, WA, USA). Blurred lines: how does cross-disciplinary research work in practice? In UBICOMP '14 ADJUNCT. Retrieved from http://ubicomp.org/ubicomp2014/proceedings/ ubicomp_adjunct/workshops/HomeSys/p963-mallaband.pdf 
Martin-de-Castro, G., López-Sáez, P., \& Navas-López, J. E. (2008). Processes of knowledge creation in knowledge-intensive firms: Empirical evidence from Boston's Route 128 and Spain. Technovation, 28(4), 222-230.

Mårtensson, P., Fors, U., Wallin, S. B., Zander, U., \& Nilsson, G. H. (2016). Evaluating research: A multidisciplinary approach to assessing research practice and quality. Research Policy, 45(3), 593-603.

Metzger, N. \& R. N. Zare (1999). Interdisciplinary research: From belief to reality. Science 283(5402), 642-643. DOI: 10.1126/science.283.5402.642

Millar, M. M. (2013). Interdisciplinary research and the early career: The effect of interdisciplinary dissertation research on career placement and publication productivity of doctoral graduates in the sciences. Research Policy, 42(5), 11521164.

Mitchell, V., Leder-Mackley, K., Pink, S., Escobar-Tello, C., Wilson, G, T. \& Bhamra, T. (2014). Situating digital interventions: mixed methods for $\mathrm{HCI}$ research in the home. Interacting with Computers, iwu034. doi: 10.1093/iwc/iwu034

Newell, S., \& Swan, J. (2000). Trust and inter-organizational networking. Human relations, 53(10), 1287-1328.

Palmer, J., Terry, N., Firth, S. and Leslie, I. (2015). 'Costing Monitoring Equipment for a Longitudinal Energy Survey'. Department of Energy and Climate Change.

Porac, J. F., Wade, J. B., Fischer, H. M., Brown, J., Kanfer, A., \& Bowker, G. (2004). Human capital heterogeneity, collaborative relationships, and publication patterns in a multidisciplinary scientific alliance: a comparative case study of two scientific teams. Research Policy, 33(4), 661-678.

Quiggin, D., \& Buswell, R. A. (2016). The implications of heat electrification on national electrical supply-demand balance under published 2050 energy scenarios. Energy, 98, pp.253-270, ISSN: 0360-5442. DOI: 10.1016/j.energy.2015.11.060.

Rafols, I., Leydesdorff, L., O'Hare, A., Nightingale, P., \& Stirling, A. (2012). How journal rankings can suppress interdisciplinary research: A comparison between innovation studies and business \& management. Research Policy, 41(7), 12621282.

REF (2014). REF2014: Research Excellence framework. Higher Education Funding Council for England. Assessed online (9/3/16): http://www.ref.ac.uk/pubs/\#content

Research Council's UK (2015). RCUK delivery plan 2015/2016. Technical report, Research Council's UK. 
Rhoten, D. (2004). Interdisciplinary research: Trend or transition. Items and Issues 5(1-2), 6-11. Retrieved from http://www.ncar.ucar.edu/Director/survey/Interdisciplinary\%20Research\%20 Trend\%20or\%20Transition.v2.pdf

Saddon, S. (2015). Integrating social science into energy research: A reality check from those on the inside. Work in preparation for forthcoming article

Shahin, J., Meyer, T. Kloza, D. \& Biedenkopf, K. (2014). Building bridges, breaking barriers: The smart approach to distance between disciplines in research projects. Technical report, European Commission. Retrieved from http://www.ies.be/files/141022MultiDiscFINAL.pdf

Sovacool, B. K. (2014). What are we doing here? Analyzing fifteen years of energy scholarship and proposing a social science research agenda. Energy Research \& Social Science, 1, 1-29.

Sovacool, B., Ryan, S., Stern, P., Janda, K., Rochlin, G., Spreng, D., Pasqualetti, M., Wilhite, H. \& Lutzenhiser, L. (2015). Integrating social science in energy research. Energy Research \& Social Science 6(1), 95-99. doi:10.1016/j.erss.2014.12.005

Togia, A., \& Tsigilis, N. (2006). Impact factor and education journals: a critical examination and analysis. International Journal of Educational Research, 45(6), 362-379.

Wang, J. (2016). Knowledge creation in collaboration networks: Effects of tie configuration. Research Policy, 45(1), 68-80.

Waterton, C., Norton, L. \& Morris, J. (2006). Understanding Loweswater: Interdisciplinary research in practice. Agricultural Economics 57(2), 277-293. doi: $10.1111 / \mathrm{j} .1477-9552.2006 .00052 . x$

Winskel, M., Ketsopoulou, J. and Churchouse, T. (2015). UKERC Interdisciplinary Review: Research Report Final Version, April 2015. Assessed online (27/2/16): http://www.ukerc.ac.uk/publications/ukerc-interdisciplinary-review-researchreport.html

Whitley, R. The fragmented state of management studies: Reasons and consequences. Journal of Management Studies, 1984, 331-48.

Cummings, J. N., \& Kiesler, S. (2007). Coordination costs and project outcomes in multi-university collaborations. Research Policy, 36(10), 1620-1634.

Younglove-Webb, J., Gray, B., Abdalla, C. W., \& Purvis-Thurow, V. (1999). The dynamics of multidisciplinary research teams in academia. The Review of Higher Education 22(4), 425-440, doi: 10.1353/rhe.1999.0019 